\title{
Marked Hyperprolactinemia Caused by Carotid Aneurysm
}

\author{
Susan R. Kahn, Richard Leblanc, Abbas F. Sadikot and I. George Fantus
}

\begin{abstract}
Background: Pituitary dysfunction caused by intracranial aneurysms is rare. We report a patient with the unique feature of hyperprolactinemia to a degree previously seen only with prolactinsecreting tumours. Method: Case report. Result: A 42-year-old woman had a galactorrhea, left-sided headache, reduced vision in the left eye and a left temporal hemianopsia. Serum prolactin was elevated $(365 \mu \mathrm{g} / \mathrm{L})$. Cranial computed tomography $(\mathrm{CT})$ revealed a suprasellar mass, which carotid angiography showed to be a left internal carotid artery aneurysm. At craniotomy, this aneurysm and a smaller one of the ophthalmic artery were repaired, and the patient's vision returned to normal. The prolactin level fell to normal. Follow-up CT showed no evidence of pituitary adenoma or hypothalamic lesion. Conclusions: Carotid aneurysm can cause reversible pituitary dysfunction. A prolactin level $>300 \mu \mathrm{g} / \mathrm{L}$ is not a reliable cut-off for distinguishing prolactin-secreting adenomas from other causes of elevated prolactin. A co-existing prolactinoma was felt to be ruled out by both a normal CT scan and normal prolactin levels following aneurysm repair. Patients with marked hyperprolactinemia should be considered for angiography or MRI to rule out carotid aneurysm, since the consequences of pituitary exploration in this setting are potentially grave.
\end{abstract}

RÉSUMÉ: Hyperprolactinémie importante due à un anévrisme de la carotide. Introduction: Une dysfonction pituitaire cousée par un anévrisme intracrânien est rare. Nous rapportons un cas inusité d'hyperprolactinémie à un niveau décrit antérieurement seulement dans les cas de tumeurs sécrétant de la prolactine. Méthode: Report d'un cas. Résultats: Une femme âgée de 42 ans s'est présentée avec une histoire de galactorrhée, d'hémicrânie gauche et de baisse de la vision de l'oeil gauche, et une hémianopsie temporale gauche. La prolactine sérique était élevée $(365 \mu \mathrm{g} / \mathrm{L})$. La tomodensitométrie cérébrale (CT) a montré une masse suprasellaire et l'angiographie carotidienne a révélé qu'il s'agissait d'un anévrisme prenant naissance sur la carotide interne gauche. À la crâniotomie, cet anévrisme et un autre plus petit sur l'artère ophtalmique ont été resséqués et la patiente a recouvré une vision normale par la suite. Le niveau de prolactine s'est abaissé à normale. Le suivi par CT n'a montré aucun signe d'adénome pituitaire ou de lésion hypothalamique. Conclusions: L'anévrisme de la carotide peut causer une dysfonction pituitaire réversible et qu'un niveau de prolactine $>300 \mu \mathrm{g} / \mathrm{L}$ n'est pas un critère fiable pour distinguer l'adénome sécrétant de la prolactine des autres causes d'hyperprolactinémie. Nous avons déterminé que la possibilité d'un prolactinome coexistant était éliminée par le CT scan normal au cours du suivi et par le fait que le niveau de prolactine s'est normalisé suite à la chirugie. Les cas d'hyperprolactinémie marquée on devraient donc penser à faire une angiographie ou une RMN pour éliminer un anévrisme carotidien parce que les conséquences d'une exploration pituitaire dans une telle situation peuvent être graves.

Can. J. Neurol. Sci. 1997; 24: 64-66

Carotid aneurysm is a rare cause of pituitary dysfunction. ${ }^{1-3}$ Because the clinical presentation may differ little from that of a pituitary tumour, it is crucial to diagnose the aneurysm prior to surgical exploration of the sella.

We report the case of a patient with pituitary dysfunction caused by a giant carotid aneurysm, in whom a unique feature was hyperprolactinemia to a degree previously accepted to be pathognomonic of a prolactin-secreting tumour. ${ }^{4}$

\section{CASE Report}

A 42-year-old woman was admitted to our institution because of galactorrhea of four months duration. Past medical history included five normal pregnancies and a hysterectomy for uterine fibroids. Two years prior to admission, she noted intermittent left hemicranial headaches which radiated to her left eye. One year later, she developed blurred vision in the left eye. Six months before admission, she noted decreased libido and a 25 pound weight loss followed by spontaneous bilateral galactorrhea. She took no medications, and denied polyuria, polydipsia, cold intolerance or changes in her appearance.

From the: Division of Endocrinology and Metabolism, Department of Medicine, Royal Victoria Hospital (S.R.K., I.G.F.); Department of Neurosurgery, Montreal Neurological Hospital and Institute (R.L., A.F.S.), McGill University, Montreal. RECEIVED FEBRUARY 13, 1996. ACCEPTED IN FINAL FORM AUGUST 6, 1996. Reprint requests to: Dr. Susan R. Kahn, Jewish General Hospital, 3755 Cote Ste. Catherine Room G-050, Montreal, Quebec, Canada H3T 1 E2 
The general physical exam was unremarkable, except for bilateral expressible galactorrhea. Neurological exam was notable for diminished visual acuity (20/200) and a temporal upper quadrantic hemianopsia in the left eye. Complete blood count and serum biochemistry were normal. Normal values were obtained for serum thyroxine, free thyroxine index, triiodothyronine, thyroid stimulating hormone, luteinizing hormone, follicle stimulating hormone and growth hormone. The 8 a.m. cortisol was low ( $160 \mathrm{nmol} / \mathrm{L}$; normal $248-690)$; the 4 p.m. cortisol was normal (165 nmol/L; normal $83-414)$. Serum prolactin was markedly elevated $(365 \mu \mathrm{g} / \mathrm{L}$; normal $<25)$.

Dynamic pituitary function testing was performed via injection of thyrotropin releasing hormone (TRH) $200 \mu \mathrm{g}$ i.v., CZI insulin $0.1 \mu / \mathrm{kg}$ i.v., and luteinizing hormone-releasing hormone $100 \mu \mathrm{g}$ s.c. There was a blunted TSH response to TRH and LH response to LHRH. Prolactin, which was $363 \mu \mathrm{g} / \mathrm{L}$ at baseline, rose to a peak of 499 at 30 min after TRH. Hypoglycemia was not achieved, making the interpretation of the blunted cortisol and growth hormone response impossible.

Skull X-ray revealed enlargement of the sella turcica and chiasmatic groove (Figure 1). Non-contrast CT scanning of the cranium demonstrated a suprasellar mass eroding the posterior clinoid (Figure 2). The history of severe unilateral headaches beginning eighteen months prior to the onset of galactorrhea and the documentation of assymetrical visual changes led to suspicion of a possible cause other than prolactinoma. Carotid angiography was performed and showed a $2 \times 2 \mathrm{~cm}$ partially thrombosed aneurysm arising from the left internal carotid artery, above the anterior clinoid process (Figure 3). An MRI scan was not performed because of the perceived urgency of performing surgery before aneurysmal rupture.

At craniotomy a large aneurysm arising from the left paraclinoid internal carotid artery above the opthalmic artery was found. The aneurysm ballooned upward and posteriorly, compressing the optic nerve, optic chiasm, and hypothalamus. There was also a smaller aneurysm at the origin of the ophthalmic artery which had not been appreciated on angiography. Both aneurysms were clipped without incident.

Post-operatively, the patient noted improved vision in the left eye (20/40). The post-operative angiogram showed two surgical clips at the level of the previous aneurysms and no evidence of residual aneurysm (Figure 4). Three months post-operatively the galactorrhea resolved, but the prolactin level remained elevated $(77 \mu \mathrm{g} / \mathrm{L})$. Eighteen months after the surgery, the prolactin level was still elevated $(58 \mu \mathrm{g} / \mathrm{L})$. The patient did not return for follow-up until four years after surgery, at which time the prolactin level was normal $(19 \mu \mathrm{g} / \mathrm{L})$, as were the TSH and prolactin responses to TRH infusion. A high resolution CT scan of the brain with coronal cuts of the sella done at this time showed no evidence of adenoma of the pituitary or lesions of the hypothalamus (Figure 5). An MRI scan was not performed because of the presence of surgical clips.

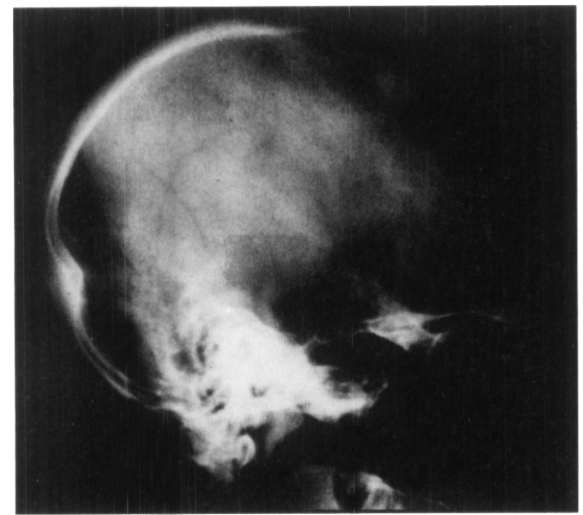

Figure 1: Pre-operative skull X-ray showing elongation of the sella turcica including the chiasmatic groove.

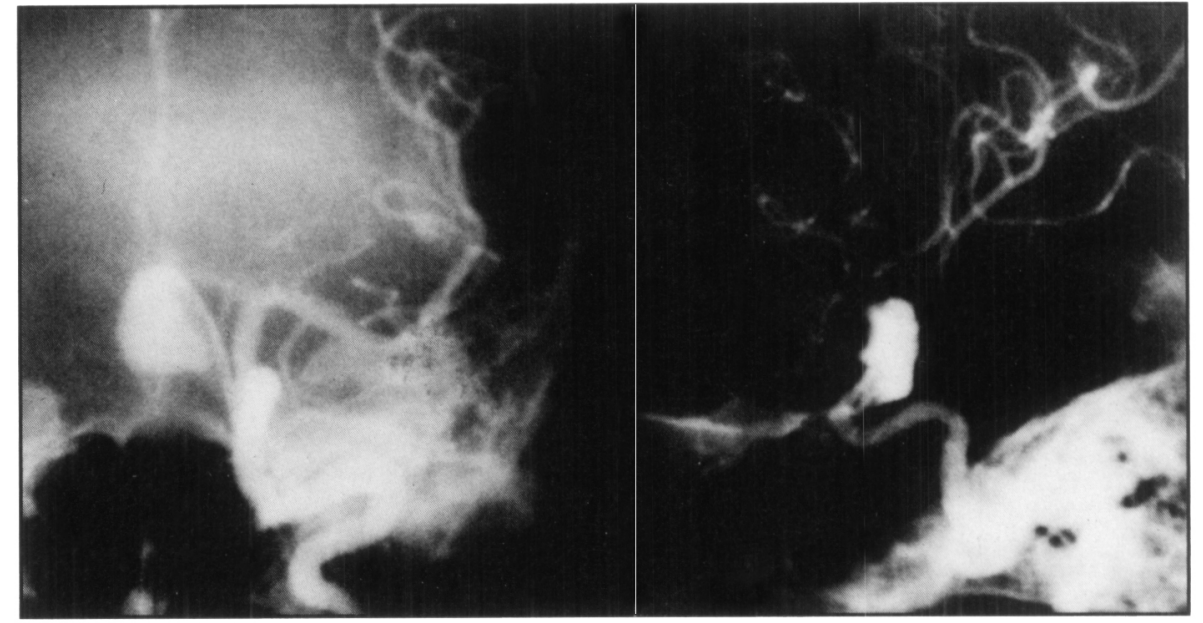

Figure 3: Pre-operative left internal carotid angiogram, antero-posterior and lateral projections, showing a partially thrombosed, $2 \times 2 \mathrm{~cm}$ aneurysm arising from the left internal carotid artery posteromedially to the origin of the left ophthalmic artery.

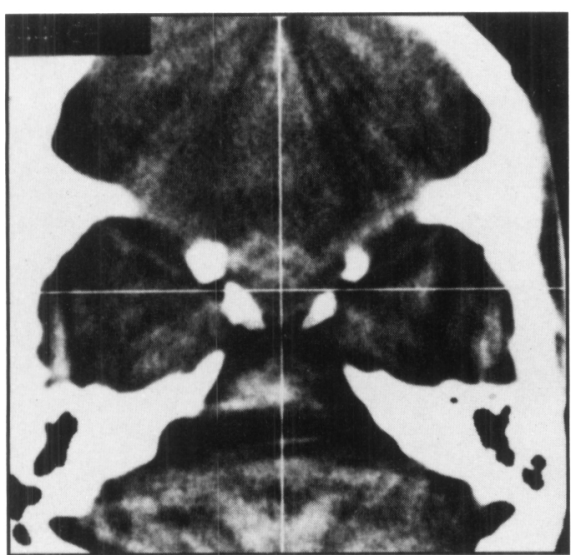

Figure 2: Pre-operative unenhanced CT scan demonstrating a hyperdense lesion in the region of the sella.

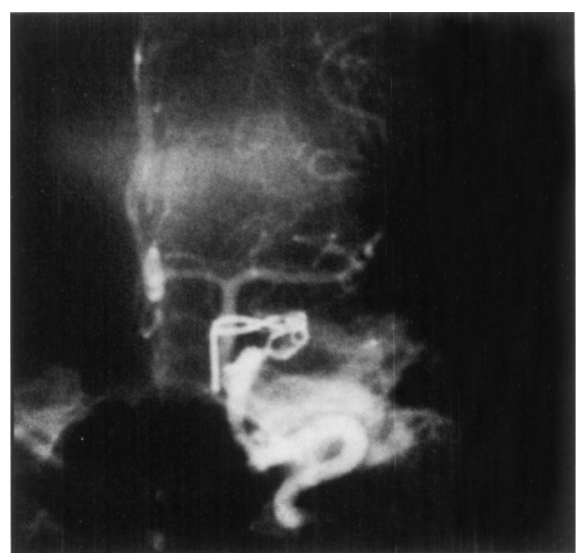

Figure 4: Post-operative left internal carotid angiogram showing exclusion of the aneurysm from the circulation. 


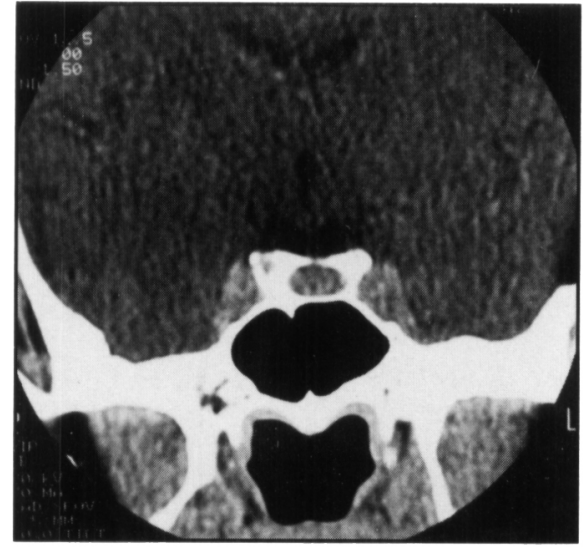

Figure 5: Enhanced CT of brain, 4 years after surgery. Coronal cuts of the sella show no evidence of micro or macroadenoma of the pituitary or lesion of the hypothalamus.

\section{Discussion}

Our patient presented with headache, visual loss and pituitary dysfunction caused by a large carotid aneurysm. After surgery, all clinical and endocrinological abnormalities resolved. The unique feature of this case is the initial marked elevation of prolactin to a degree previously associated only with prolactinsecreting tumours. ${ }^{4} \mathrm{~A}$ coexisting prolactinoma was ruled out in this patient by a normal high resolution CT scan and a prolactin level which decreased post-operatively and was normal at four years follow-up.

A study of 235 patients with galactorrhea of various causes showed that likelihood of pituitary tumour directly correlated with the prolactin level, such that all cases with prolactin concentrations above $300 \mu \mathrm{g} / \mathrm{L}$ were associated with pituitary tumours, as were $70 \%$ of cases with serum prolactin levels greater than $200 \mu \mathrm{g} / \mathrm{L} .{ }^{4}$ In a series of 205 patients with various intracranial diseases, all cases with prolactin levels greater than $90 \mu \mathrm{g} / \mathrm{L}$ were associated with pituitary tumour. ${ }^{5}$ A study of 204 patients with space-occupying sellar lesions and isolated hyperprolactinemia showed that in all cases of non-prolactinoma sellar lesions, the prolactin level was less than $130 \mu \mathrm{g} / \mathrm{L} .{ }^{6}$

The highest prolactin previously reported in association with carotid aneurysm was in a 74-year-old woman with an intrasellar carotid aneurysm, hypopituitarism, and a serum prolactin of 182 $\mu \mathrm{g} / \mathrm{L} .{ }^{7}$ Surgery was not performed, hence a post-operative prolactin level was unavailable. However, in a 59-year-old woman with panhypopituitarism and hyperprolactinemia caused by a giant intracranial aneurysm, the prolactin level returned to normal by the thirteenth post-operative day. ${ }^{3}$ This is in contrast with our case, where the prolactin level remained elevated until sometime between eighteen months and four years post-operatively.

The mechanism by which carotid aneurysm produces hyper- prolactinemia is likely via hypothalamic or pituitary stalk compression, resulting in interference with the delivery of prolactininhibiting factor to the pituitary. Two studies of patients with non-prolactin secreting sellar tumours with secondary hyperprolactinemia have, however, demonstrated a lack of correlation between suprasellar extension with compression of the pituitary stalk and degree of prolactin elevation ${ }^{6.8}$ In our patient the extremely high level of prolactin suggests an additional stimulating effect by a putative hypothalamic prolactin-stimulating factor. It is not known whether the pulsatility of an aneurysm can stimulate the secretion of such a factor or stimulate the anterior pituitary itself. Studies in experimental animals have shown that irritative lesions of the anterior hypothalamus could potentially cause release of prolactin-stimulating factor. ${ }^{9}$ The reason that the prolactin level in our patient normalized only years post-operatively is unclear, but implies reversible stimulation of prolactin-secreting cells.

In summary, our patient illustrates that carotid aneurysm is a cause of reversible pituitary dysfunction, and that a prolactin level greater than $300 \mu \mathrm{g} / \mathrm{L}$ should not be considered to be a safe cut-off in distinguishing pituitary tumour from other causes of elevated prolactin. Thus, even patients with this degree of hyperprolactinemia should be subjected to cerebral angiography or magnetic resonance imaging if there is any clinical suspicion of carotid aneurysm, since CT scanning is not reliable for this purpose and the surgical consequences of pituitary exploration in this setting are potentially grave.

\section{REFERENCES}

1. White, JC, Ballantine HT Jr. Intrasellar aneurysms simulating hypophyseal tumors. J Neurosurg 1961; 18: 34-50.

2. Kahana L, Leibovitz H, Walter L, et al. Endocrine manifestations of intracranial extrasellar lesions. J Clin Endocrinol 1962; 22: 304324.

3. Verbalis JG, Nelson PB, Robinson AG. Reversible panhypopituitarism caused by suprasellar aneurysm: the contribution of mass effect to pituitary dysfunction. Neurosurgery 1982; 10: 604-611.

4. Kleinberg DL, Gordon LN, Frantz AG. Galactorrhea: a study of 235 cases, including 48 with pituitary tumours. N Engl J Med 1977; 296: 589-600.

5. Balagura S, Frantz AG, Housepian EM, Carmel PW. The specificity of serum prolactin as a diagnostic indicator of pituitary adenoma. J Neurosurg 1979; 51: 42-46.

6. Riedel M, Noldus J, Saeger W, Ludecke DK. Sellar lesions associated with isolated hyperprolactinemia. Acta Endocrinol 1986; 113: 196-203.

7. Ooi TC, Russell NA. Hypopituitarism resulting from intrasellar carotid aneurysm. Can J Neurol Sci 1986; 13: 70-71.

8. Kruse A, Astrup J, Gyldensted C, Cold GE. Hyperprolactinemia in patients with pituitary adenomas. The pituitary stalk compression syndrome. Br J Neurosurg 1995; 9: 453-457.

9. Molitch, ME. Pathologic hyperprolactinemia. Endocrinol Metab Clin North Am 1992; 21 : 877-901. 